\title{
THE MEASUREMENT OF CORNEAL THICKNESS AND ITS APPLICATION TO KERATOPLASTY*
}

BY

\author{
A. LISTER, A. S. PHILPS, AND M. LANGHAM \\ Institute of Ophthalmology, London
}

ONE of the main problems of corneal surgery is presented by variations in thickness of the pathological cornea. In the realm of penetrating keratoplasty undue overall thickness or thinness of the recipient cornea may jeopardize the chances of a clear graft, or local variations in thickness may influence the choice of the size of the graft so as to ensure that its edge may have adequate support throughout the circumference. In lamellar keratoplasty, the thickness of the portion to be removed is obviously dependent partly on the depth of the opacity and partly on the thickness of the tissue which it is safe to remove without perforation. The same applies to keratectomy.

Modern corneal trephines, such as that of Franceschetti, make it a matter of no great difficulty to gauge accurately the depth of penetration in any of these operations. The difficulty is not, so to speak, how far to go but knowing how far to go. In some cases, of course, the opacity is too dense to allow any measurement of its thickness. In the majority, however, there is sufficient transparency for the optical section to be seen with the slit lamp and its depth estimated. Estimation of the approximate depth of the optical section of the cornea by " eye" is not usually difficult, but estimation to the nearest tenth of a millimetre, which is necessary in situations such as those mentioned, requires a more precise method.

The method employed by the authors is that devised and described by Maurice and Giardini (1951), from whose paper the following slightly modified quotation is taken:

The apparatus (Figure) consists essentially of a 1 " perspex plate mounted behind the slit-lamp lens, that is, between the lens and the slit. A transverse cut about $1 \mathrm{~mm}$. wide is made centrally across this plate with a saw, and this is covered with a thin strip of coloured celluloid. The plate may be rotated by an arm which moves over a scale fixed to a mount fitting snugly over the slit-lamp arm, on which it is located by the two screws normally present.

The slit lamp is adjusted so that a narrow slit is focussed on the cornea, and the light, on direct reflection at the corneal surfaces, passes up the axis of the microscope. In this way two optical sections of the cornea will be seen on looking into the microscope, a normal "white" one, which is displaced in the field of view as the perspex plate is rotated, and a less intense coloured one, virtually restricted to the epithelial reflex, which remains stationary. To carry out a determination, the plate is rotated until the white endothelial reflex is brought into alignment with the coloured epithelial reflex with which it is comparable in brightness. The angle of rotation is a measure of the corneal thickness and is interpreted as such by reference to a graph. 


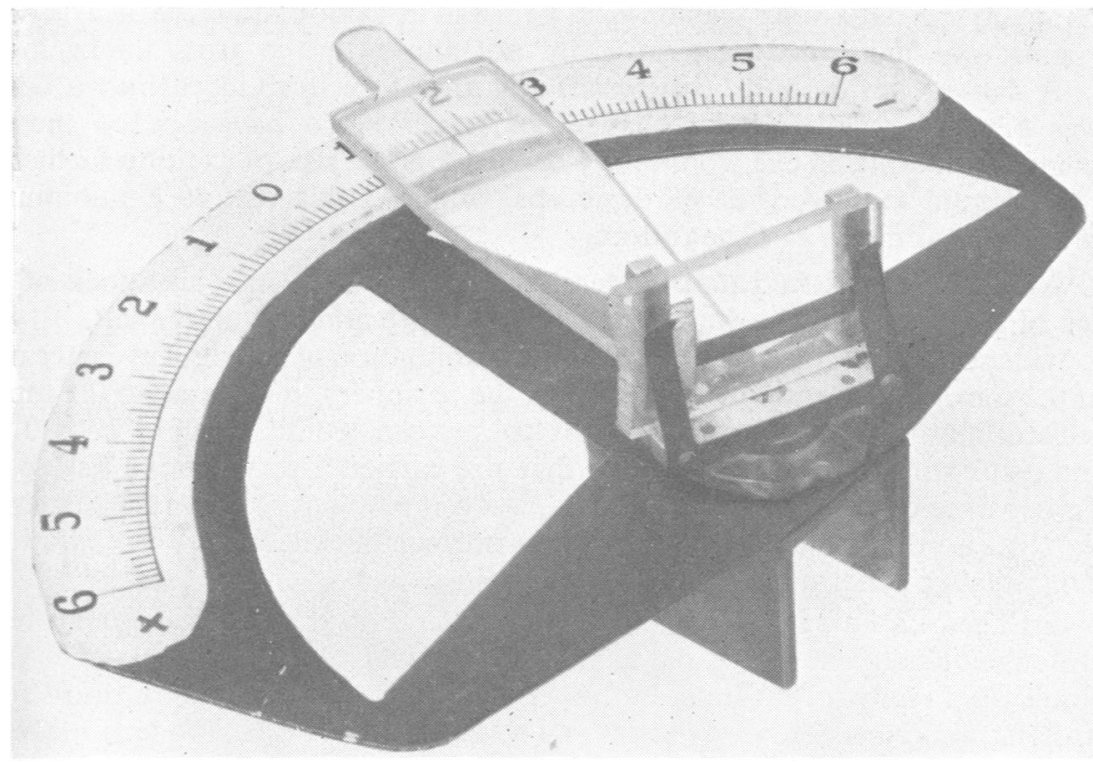

FiguRE.-General view of the optical apparatus for measuring the corneal thickness (Maurice and Giardini, 1951).

By this method the thickness of any part of the cornea, provided it is sufficiently transparent, can be simply and quickly measured.

\section{Case Reports}

The following case notes illustrate the application of the method:

(1) This patient had been a miner until 1948 when a mine explosion destroyed his right eye completely and gravely damaged the left, many particles of foreign matter penetrating inside the globe.

Examination.-In 1952 the state of the left eye was as follows:

Vision-hand movements;

Cornea-fairly dense opacities due to multiple perforations, and a few clear areas where the cornea had been protected by the lid.

Iris-missing above.

Lens-missing.

Treatment.-Because of the aphakia and the near certainty that after so many perforations of the globe the vitreous would be fluid, a penetrating graft could not be done, and an $8 \mathrm{~mm}$. lamellar graft to a depth of $0.4 \mathrm{~mm}$., i.e. the safe depth for a normal cornea, was performed in February, 1952. Much corneal opacity had to be left behind and his vision was hardly improved, though he could sometimes count fingers. It was felt that something more should be attempted and the development of corneal measurement offered the chance of a better lamellar graft. Measurement of the cornea showed it to be $0.7 \mathrm{~mm}$. thick in the centre and $0.8 \mathrm{~mm}$. at the periphery, so that a fresh graft to a depth of $0.6 \mathrm{~mm}$. could be introduced.

Results.-The patient is now convalescent and it seems evident that his vision is going to be much improved by this second operation.

(2) A somewhat similar case was one of sympathetic ophthalmitis. The exciting eye 
had been removed, and the sympathizing eye had a semi-opaque cornea. An initial lamellar graft was ineffective because it did not allow for the gross thickening of the cornea. A subsequent $\mathbf{0 . 6}-\mathrm{mm}$. thick graft was therefore introduced into a bed whose depth was $0.9 \mathrm{~mm}$. - with greater chances of success. To have opened the anterior chamber in a sympathizing eye would have carried a grave risk of exciting further inflammation. Accurate measurement of the cornea reduced this risk to a minimum while allowing a maximal depth of penetration.

(3) A woman, aged 39, had had bilateral corneal nebulae since an attack of measles at the age of $1 \frac{1}{2}$ years. Vision was $2 / 60$ in the right eye and $6 / 60$ in the left.

It was evident that her corneae were thin and examination of the right eye gave measurements of $0.2 \mathrm{~mm}$. in the centre and $0.3 \mathrm{~mm}$. at the periphery, increasing to $0.5 \mathrm{~mm}$. at the corneo-scleral margin. A penetrating graft to succeed would have to be $9.0 \mathrm{~mm}$. in width and a sub-total penetrating graft of that size carried a very definite risk to the eye. The opacities were deep as well as superficial, but a preliminary $9.0 \mathrm{~mm}$. tectonic lamellar graft has been applied to bring the cornea to normal thickness, as a preparation for a subsequent smaller penetrating graft.

(4) A girl aged 23 had sustained a lime burn of the right cornea 4 years previously. After prolonged treatment which included a tarsorrhaphy and later a keratectomy, the eye was quiet and ready for grafting, but, in view of the bad prognosis for grafts following lime burns, it was considered wisest to make the graft a lamellar one. Measurement showed the thickness of the cornea to be between 0.6 and $0.65 \mathrm{~mm}$. except at one point near the centre where it was $0.48 \mathrm{~mm}$. To avoid perforating, a $6 \mathrm{~mm}$. lamellar graft $0.45 \mathrm{~mm}$. in thickness was introduced. Measurement 2 weeks later showed the graft to be 0.52 to $0.56 \mathrm{~mm}$. in thickness and its bed to be $0.15 \mathrm{~mm}$. The apparent increase in thickness is accounted for by post-operative swelling. The bed of the graft was transparent though vascularized and the ultimate corrected vision was 6/9 (from counting fingers).

(5) This patient was suffering from mustard keratitis, the left eye being blind. A lamellar graft to the right (good) eye became partially detached, and removal of the raised portion left a thin but relatively clear area of cornea with considerable visual improvement. It was hoped that removal of the remainder of the graft which was semiopaque would bring about further improvement. The area of the second portion of cornea to be removed and its depth were carefully charted, and what would otherwise be a matter of hazardous guesswork was thus given precision and relative safety.

(6) A final case is worthy of mention because pre-operative measurement was omitted with nearly disastrous results. The patient was a young Indian in whom a Mooren's ulcer had left a thin semi-opaque cornea. A preliminary lamellar graft was proposed, to be followed probably by a penetrating one. The cornea was thinner than was expected and an extensive perforation was made with a trephine at its first turn. Since a penetrating graft on such a thin cornea would only have made matters worse the operation was abandoned after closing the perforation with direct sutures.

These examples of cases in which corneal measurement has and has not been employed demonstrate the added safety which it gives to keratoplasty. Furthermore, post-operative as well as pre-operative measurement provides a gauge of both instrumental and technical accuracy which must lead to improvement in method besides adding to the interest of the operation. The technique also provides a promising means of studying at least one aspect of the post-operative behaviour of grafts.

\section{REFERENCE}

Maurice, D. M., and Giardini, A. A. (1951). British Journal of Ophthalmology, 35, 169, fig. 1. 